\title{
Jovens designers: um relato de experiência de prototipação participativa
}

\author{
Valeria Argôlo Rosa de Queiroz ${ }^{1}$, Diego Zabot' ${ }^{1}$, Daniel Domingos Alves ${ }^{12}$, Ila \\ Mascarenhas Muniz ${ }^{1}$, Ecivaldo de Souza Matos ${ }^{1}$ \\ ${ }^{1}$ Departamento de Ciência da Computação - Instituto de Matemática e Estatística - \\ Universidade Federal da Bahia (UFBA) - Salvador - BA - Brasil \\ 2Instituto Federal de Mato Grosso (IFMT) - Campus Rondonópolis \\ Rondonópolis - MT - Brasil \\ \{valeria.rosa, diego.zabot, daniel.domingos, ila, ecivaldo\}@ufba.br
}

\begin{abstract}
This article presents a report of an experience on prototyping in the context of a workshop with young people from a low income community. The objectives were to introduce young people to the importance of prototyping a product before developing it and teaching prototyping in a participatory way, involving possible users of the product. The activity was carried out in six stages, using some participatory techniques. The results indicate that, even with some limitations, it was possible to achieve the proposed objectives, involving young people in a participatory way in prototyping the product, generating creative ideas.
\end{abstract}

Resumo. Este artigo apresenta um relato de experiência sobre prototipação no contexto de uma oficina com jovens de uma comunidade de baixa renda. Os objetivos foram apresentar aos jovens a importância de prototipar um produto antes de desenvolvê-lo e ensinar a fazer prototipação de forma participativa, envolvendo os possíveis usuários do produto. A atividade foi realizada em seis etapas, utilizando algumas técnicas participativas. Os resultados indicam que, mesmo com algumas limitações, foi possível atingir os objetivos propostos, envolvendo os jovens de forma participativa na prototipação do produto, gerando ideias criativas.

\section{Introdução}

Para possibilitar a compreensão e interação do usuário com a solução de design, Rogers, Sharp e Preece (2013) pontuam a construção de protótipos como uma abordagem extremamente poderosa. Para elas, "a atividade de construir protótipos estimula a reflexão sobre o design" [Rogers, Sharp e Preece 2013, p. 391]. As autoras ainda destacam alguns propósitos relacionados à construção de protótipos: a viabilidade técnica de uma ideia tem que ser testada; alguns requisitos vagos precisam ser esclarecidos; precisa ser feito algum teste e avaliação com usuários, entre outros. Qualquer um desses propósitos irá influenciar o tipo de protótipo que será construído.

No design de interação, a atividade de prototipação constitui uma das etapas do processo e envolver usuários finais e outros interessados em todas as etapas é um princípio da abordagem de design participativo (DP) que, em essência, pode ser 
VII Congresso Brasileiro de Informática na Educação (CBIE 2018)

Anais dos Workshops do VII Congresso Brasileiro de Informática na Educação (WCBIE 2018)

definido como "um processo de investigar, compreender, refletir, estabelecer, desenvolver e apoiar a aprendizagem mútua entre múltiplos participantes na reflexão-em ação coletiva"1 [Simonsen and Robertson 2012, p. 2].

Este artigo tem como objetivo apresentar um relato de experiência sobre prototipação participativa elaborado no contexto do projeto de extensão Café Digital, o qual é promovido pelo Grupo de Pesquisa e Extensão em Informática, Educação e Sociedade - Onda Digital, do Departamento de Ciência da Computação (DCC) do Instituto de Matemática e Estatística (IME) da Universidade Federal da Bahia. O projeto de extensão trata-se de um fórum de debates, com previsão de ocorrer em cinco edições ao longo do ano, cuja finalidade é discutir cidadania, ciência e tecnologia.

$\mathrm{Na}$ primeira edição, paralelamente ao fórum de discussão, foram realizadas oficinas práticas e lúdicas com crianças e jovens atendidos por uma ONG, localizada em uma comunidade de baixa renda. O Grupo de Pesquisa e Extensão Onda Digital já oferece cursos de iniciação à computação e de programação na $\mathrm{ONG}$ e pretende propor um novo módulo de programação de aplicativos móveis. Por isso, foi escolhido apresentar uma oficina de prototipação de um artefato digital, com o objetivo de apresentar aos participantes a importância de prototipar um produto antes de desenvolvê-lo e como fazer prototipação de forma participativa, envolvendo possíveis usuários do produto.

Este artigo está estruturado da seguinte forma: a seção 2 apresenta a fundamentação teórica; posteriormente, a seção 3 apresenta a metodologia; a seção 4 aborda a aplicação da oficina de prototipação; a seção 5 retrata resultados e análise e, por fim, a seção 6 apresenta as considerações finais do artigo.

\section{Fundamentação Teórica}

Nas ações que compõem o relato de experiência deste artigo, adota-se como referencial teórico design de interação e DP.

\subsection{Design de Interação}

Para Rogers, Sharp e Preece (2013), o termo design de interação tem sido cada vez mais aceito como um termo "guarda-chuva", pois cobre diversos aspectos, por exemplo, design de interface do usuário, design centrado no usuário, web design, design de experiência e design de sistemas interativos. Para as autoras, design de interação é "projetar produtos interativos para apoiar o modo como as pessoas se comunicam e interagem em seus cotidianos, seja em casa ou no trabalho" (p.8).

De forma simples, porém abrangente, Lowgren (2014) argumenta que design de interação é modelar artefatos digitais para serem usados pelas pessoas e a Interaction Design Association (2017) afirma que "Design de Interação define a estrutura e o comportamento de sistemas interativos".

Rogers, Sharp e Preece (2013, p. 6) também afirmam que "projetar produtos interativos requer levar em conta de que forma, onde e por quem serão utilizados". Para isso, é concebido um processo de design de interação constituído de várias atividades, que são: i) estabelecer requisitos (atividade que tem o objetivo de entender as

\footnotetext{
${ }^{1}$ Todas as traduções do inglês foram feitas pelos autores.
} 
VII Congresso Brasileiro de Informática na Educação (CBIE 2018)

Anais dos Workshops do VII Congresso Brasileiro de Informática na Educação (WCBIE 2018)

necessidades dos usuários); ii) projetar alternativas (atividade que proporciona ao usuário sugerir ideias para satisfazer os requisitos); iii) prototipar (atividade que permite a interação do usuário com o design de produtos, por meio da construção de protótipos) e iv) avaliar o design (atividade que determina a usabilidade e aceitabilidade do produto final).

$\mathrm{Na}$ realização dessas atividades é importante envolver os usuários para que os desenvolvedores possam compreender as necessidades dos usuários e, assim, construir um produto mais adequado e usável.

Entender as necessidades do usuário possibilita estabelecer requisitos, que determinarão o que será mais apropriado para diferentes tipos de interface e como será feito o processo de entrada e saída de informações. Após o estabelecimento dos requisitos, os usuários são envolvidos nas demais etapas do processo em ciclos de design-avaliação-redesign. Rogers, Sharp e Preece (2013) afirmam que o foco do design de interação é avaliar se o produto é realmente adequado e isso geralmente é possível com uma abordagem centrada nos usuários, envolvendo-os em todo o processo. Nesse sentido, o DP é uma possível solução, uma vez que tem como premissa central, a participação ativa dos potenciais usuários no processo de design.

\title{
2.2 - Design Participativo
}

O DP originou-se na Escandinávia, na década de 70 e tem como princípio a participação dos usuários finais e as partes interessadas no processo de construção do produto ao longo de todo o ciclo de design e desenvolvimento [da Rocha e Baranauskas 2003, da Silva 2012].

Para Simonsen e Robertson (2012, p. 2), DP é:

\begin{abstract}
um processo de investigar, compreender, refletir, estabelecer, desenvolver e apoiar a aprendizagem mútua entre múltiplos participantes na 'reflexão-em-ação' coletiva. Os participantes normalmente assumem os dois papéis principais dos usuários e designers onde os designers se esforçam para aprender as realidades da situação dos usuários enquanto os usuários se esforçam para articular seus objetivos desejados e aprender meios tecnológicos adequados para obtê-los.
\end{abstract}

Sanders (2002, p. 1) explica que:

\begin{abstract}
Experiência participativa não é simplesmente um método ou conjunto de metodologias, é uma mentalidade e uma atitude sobre pessoas. É a crença de que todas as pessoas têm algo a oferecer para o processo de design e que eles podem ser ambos articulados e criativos quando administrados com as ferramentas adequadas para se expressarem.
\end{abstract}

Muller, Haslwanter e Dayton (1997) apresentam um quadro taxonômico com uma lista que inclui 61 técnicas de Design Participativo, organizadas conforme a fase do ciclo de vida de software em que pode ser utilizada (identificação do 
VII Congresso Brasileiro de Informática na Educação (CBIE 2018)

Anais dos Workshops do VII Congresso Brasileiro de Informática na Educação (WCBIE 2018)

problema, levantamento e análise de requisitos, design, avaliação, customização e re-design) e conforme o local de atividade que poderá ser usado: no domínio do usuário, no domínio dos profissionais (ou pesquisadores) ou em um espaço intermediário entre os dois domínios.

Para Brandt, Binder e Sanders (2013) é um desafio grande determinar quais técnicas são mais adequadas a determinado contexto e quais técnicas são apropriadas para cada fase do processo. Rocha e Baranauskas (2003, p. 136) afirmam que as técnicas participativas podem ser aplicadas em todas as fases do ciclo de vida de um software, sendo mais recorrente na fase de design.

\section{Metodologia}

Trata-se de um estudo descritivo, tipo relato de experiência, elaborado no contexto de um projeto de extensão por membros (mestrandos e doutorandos) do Grupo de Estudos em Interação Humano-Computador (GEIHC) do Grupo de Pesquisa e Extensão Onda Digital da UFBA.

\subsection{Planejamento da atividade}

A oficina de prototipação foi planejada para ser realizada em seis etapas, conforme apresentado na Figura 1. Foi definido um tempo máximo de duas horas para a execução da oficina.

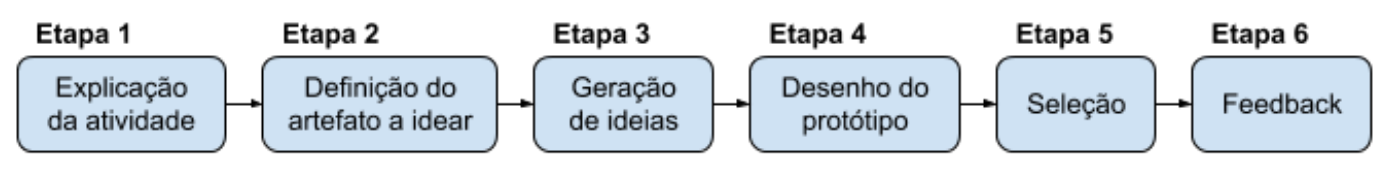

Figura 1. Etapas da atividade de prototipação. Fonte: autores

\section{Etapa 1 - Explicação da atividade}

Refere-se à explicação pelos pesquisadores/mediadores aos participantes os conceitos fundamentais sobre design de interação, design participativo e a importância da atividade de prototipação.

\section{Etapa 2 - Definição do artefato a idear}

Constitui-se da definição do artefato a ser ideado pelos participantes, mostrando exemplos e discutindo sobre o conhecimento do artefato.

\section{Etapa 3: Geração de ideias}

Essa etapa tem o escopo de gerar ideias sobre o artefato a produzir, apresentado na etapa anterior.

\section{Etapa 4: Desenho do protótipo}

Nessa etapa é realizada a prototipação de baixa fidelidade do artefato, com as ideias sugeridas e escolhidas na etapa anterior.

Etapa 5: Seleção e discussão

Nessa etapa os participantes discutem e selecionam democraticamente entre os protótipos criados a solução de design mais adequada. 
VII Congresso Brasileiro de Informática na Educação (CBIE 2018)

Anais dos Workshops do VII Congresso Brasileiro de Informática na Educação (WCBIE 2018)

\section{Etapa 6: Feedback}

A atividade finaliza com um feedback dos participantes sobre a atividade realizada e a compreensão deles a respeito da importância de se realizar prototipação, antes da fase de desenvolvimento.

\section{2 - Técnicas e materiais de apoio para a realização da atividade}

Foram definidas algumas técnicas e materiais de apoio a serem utilizados nas etapas da oficina e foi decidido que o artefato a ser projetado seria um 'brinquedo inteligente'.

$\mathrm{Na}$ etapa 2, para apresentar aos participantes o conceito de brinquedo inteligente, foi utilizado o vídeo The Educational Toy Dino Unlike Any Other ${ }^{2}$. Nas etapas 3 e 4, foram escolhidas a técnica de Brainstorm, para levantar os requisitos do artefato, e a técnica de Braindraw, para fazer o design de interface.

Segundo Rosa (2017), Brainstorm é uma técnica considerada participativa, porque possibilita o envolvimento de usuários em uma "tempestade de idéias", ou seja, possibilita sugestão de ideias novas e melhores pelos usuários. É uma "técnica utilizada para levantar requisitos e aprender sobre novas características que os usuários apreciariam em um produto" [Barbosa e Silva 2010, p. 155]. Os participantes escrevem as próprias sugestões em relação ao problema enunciado em notas autoadesivas. As notas são discutidas e examinadas em grupo.

Os seguintes materiais de apoio foram utilizados na aplicação do brainstorm: notas autoadesivas, lápis, borracha.

Rosa (2017, p. 32) afirma que braindraw "é uma técnica participativa de desenho livre, onde os participantes produzem desenhos de modo colaborativo". Em círculo, com um tempo determinado, cada participante inicia um desenho que será movido a cada rodada. Em sentido horário, o papel é entregue ao participante ao lado que continuará o desenho. Esse processo só finaliza quando todos colaboram com a criação de cada um dos outros participantes.

Os materiais de apoio utilizados na aplicação do braindraw foram: cronômetro, caneta e papel de oficio A4.

\section{Aplicação da oficina de prototipação}

A oficina foi aplicada com cinco jovens (três de sexo masculino e dois de sexo feminino) atendidos por uma ONG localizada em uma comunidade de baixa renda, com faixa etária de 14 a 18 anos de idade e que tinham apenas noções básicas de informática.

Esses jovens fazem parte do projeto de inclusão digital oferecido pelo Grupo de Pesquisa e Extensão Onda Digital/UFBA. Esse grupo tem por missão contribuir com a inclusão sociodigital na Bahia, envolvendo a Universidade em ações educativas e de difusão do Software Livre [dos Santos et al., 2017].

Os jovens foram convidados a sentarem em círculo sobre um tapete. Inicialmente foi explicado, com um linguajar apropriado ao público infanto-juvenil, o

\footnotetext{
${ }^{2}$ Vídeo disponível em: https://www.youtube.com/watch?v=lpOKCTqO3ik
} 
VII Congresso Brasileiro de Informática na Educação (CBIE 2018)

Anais dos Workshops do VII Congresso Brasileiro de Informática na Educação (WCBIE 2018)

que era design de interação e a importância da atividade de prototipação no processo de design de interação (Etapa 1). Logo em seguida, foi explicado sobre o artefato a ser prototipado naquela atividade e para uma melhor compreensão sobre o brinquedo inteligente foi apresentado o vídeo The Educational Toy Dino Unlike Any Other (Etapa 2).

Após os jovens assistirem o vídeo e compreenderem sobre o que era brinquedo inteligente, a Etapa 3 foi realizada usando a técnica Brainstorm. Foi solicitado para os jovens escreverem todas as ideias que lhes viessem à mente espontaneamente sobre um brinquedo inteligente. Para isso, foi entregue, a cada membro do grupo, bloquinhos de notas autoadesivas, lápis e borracha e foi estipulado um tempo de 20 minutos para a realização dessa etapa. definidas:

Para facilitar a execução da atividade pelos jovens, algumas perguntas foram

1. O que o seu brinquedo inteligente pode fazer?

2. Qual o formato que representará o seu brinquedo inteligente?

3. Como seria a interação do usuário com o brinquedo?

Ao término da escrita das ideias, os pesquisadores-mediadores solicitaram que os jovens analisassem todas as ideias a fim de selecionar as mais adequadas para o artefato.

Para a Etapa 4 foi utilizada a técnica de Braindraw. Os pesquisadores realizaram os seguintes passos: i) explicaram a dinâmica do Braindraw; ii) distribuíram papel de oficio A4, lápis e borracha para cada membro do grupo e iii) determinaram o tempo de um minuto para os papéis girarem em sentido horário.

Seguindo para a Etapa 5, os participantes analisaram todos os desenhos e escolheram o protótipo que melhor se adequava ao que o grupo desejava. E logo em seguida, a pedido dos pesquisadores, os participantes deram um feedback de toda a atividade desenvolvida, finalizando assim, a etapa 6 . Toda a atividade participativa de prototipação foi realizada em uma hora e meia.

\section{Resultados e discussão}

Por meio das notas autoadesivas ( $c f$. Figura 2), os jovens registraram as suas ideias sobre o brinquedo inteligente, destacando o formato que o brinquedo teria, as funcionalidades, qual seria o objetivo do brinquedo, entre outros. 
VII Congresso Brasileiro de Informática na Educação (CBIE 2018)

Anais dos Workshops do VII Congresso Brasileiro de Informática na Educação (WCBIE 2018)

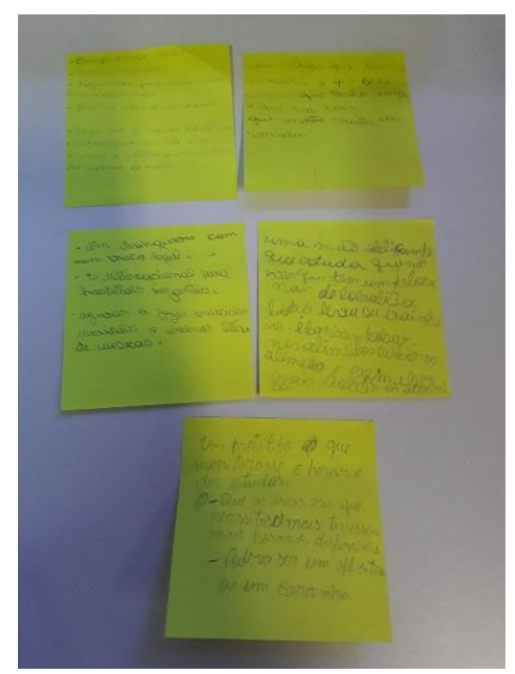

Figura 2. Resultados do Brainstorm

Das ideias sugeridas eis algumas:

- um carrinho ou um aplicativo que monitorasse os estudos;

- uma mão inteligente que auxiliasse pessoas com deficiência visual a irem ao sanitário;

- um brinquedo educativo para o ensino de música direcionado a hospitais infantis;

- um relógio que auxiliasse a contar calorias, com imagens de alimentos saudáveis e receitas;

- um brinquedo educativo que compartilhasse ideias, que servisse de despertador e ensinasse o básico de idiomas.

Observou-se que nessa etapa os jovens registraram ideias criativas e com foco nas áreas da saúde e educação. As perguntas feitas pelos pesquisadores-mediadores foram fundamentais para direcionar os participantes no objetivo da etapa. Como dizem Barbosa e Silva (2010, p. 155): "Uma sessão eficiente de brainstorming começa com uma pergunta que sumariza o objetivo de entender o que os usuários querem e precisam no produto".

Após uma análise e discussão do grupo sobre as ideias propostas, os jovens pensaram em criar uma mão inteligente por ser um elemento que possibilitaria contemplar todas as ideias propostas por cada participante, uma para cada dedo da mão. Definido isso, a fase de Braindraw serviu para desenhar colaborativamente o protótipo de baixa fidelidade do brinquedo. A Figura 3 apresenta os resultados gerados nesta etapa. 


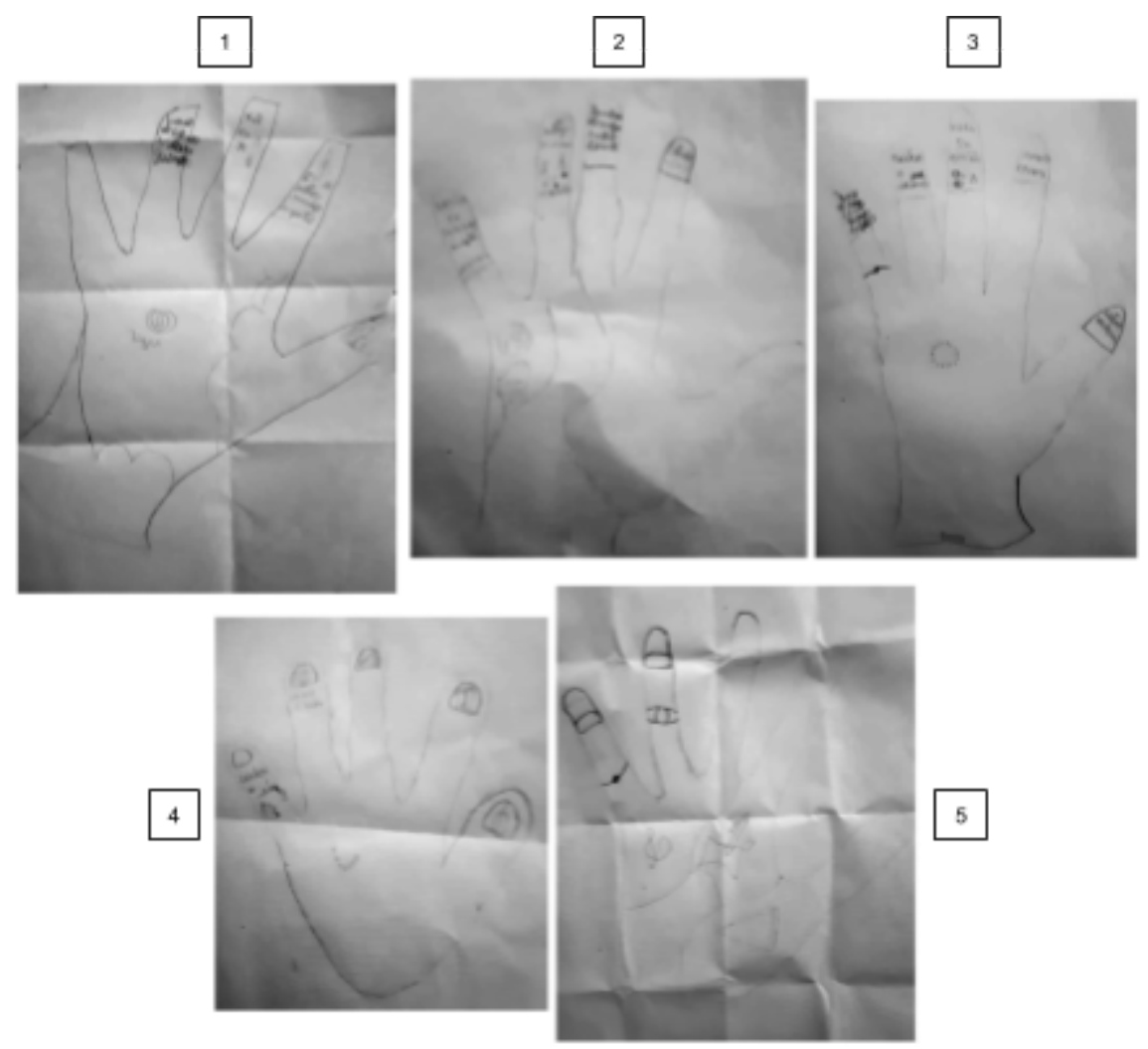

Figura 3. Resultados do Braindraw

Nos desenhos resultantes foi identificado que os jovens colocaram em cada dedo da mão inteligente a função que cada um sugeriu na atividade de Brainstorm, mediante textos (Figura 3, nos números 1, 2 e 3) e imagens de ícones relacionados à função (Figura 3, nos números 4 e 5).

Terminada a etapa de Braindraw, foi selecionado democraticamente o protótipo mais adequado: o desenho número 4 foi escolhido pela maior parte dos participantes, principalmente por ter as funções representadas por ícones.

Percebeu-se, no início da atividade, que os jovens tinham receio em expressar as próprias opiniões por causa, provavelmente, do fato de estar em um ambiente não familiar e não conhecer os pesquisadores. A técnica de Brainstorm e, em geral, o clima lúdico da oficina, ajudou a superar esta dificuldade, deixando os jovens mais participativos e entusiastas na proposta de soluções de design.

Outra percepção foi sobre algumas dificuldades na escrita dos participantes (identificadas na realização do Brainstorm), mas que não invalidaram o processo de prototipação.

Como limitação observada, destaca-se a estipulação de pouco tempo para a realização da atividade, que apesar de resultados criativos e interessantes, impossibilitou discussões e observações mais ricas e aprofundadas em todas as etapas. Assim, algumas recomendações sobre a condução de atividade de prototipação engajando jovens se fazem necessárias:

1. tempo de realização maior que $2 \mathrm{hs;}$ 
VII Congresso Brasileiro de Informática na Educação (CBIE 2018)

Anais dos Workshops do VII Congresso Brasileiro de Informática na Educação (WCBIE 2018)

2. possibilitar que os participantes definam o tipo de produto a ser prototipado;

3. promover uma discussão mais aprofundada sobre as suas necessidades individuais e coletivas referentes à comunidade;

4. promover uma discussão mais aprofundada sobre o desenho a prototipar e o desenho prototipado;

\section{Considerações Finais}

Este trabalho apresentou o relato de experiência da aplicação de uma oficina de prototipação de um artefato digital, inserido em um projeto de extensão, com um grupo de jovens que são atendidos em uma ONG localizada em uma comunidade de baixa renda e participantes de um projeto de inclusão digital promovido pelo Grupo de Pesquisa e Extensão Onda Digital/UFBA. A oficina de prototipação tinha o objetivo de apresentar aos participantes a importância de prototipar um produto antes de desenvolvê-lo e como fazer prototipação de forma participativa, envolvendo possíveis usuários do produto.

A aplicação da oficina possibilitou identificar que mesmo em pouco tempo é possível aplicar uma oficina de prototipação com jovens, mesmo tendo algumas dificuldades na escrita.

Para trabalhos futuros, pretende-se aplicar essa atividade para um maior número de jovens que irão participar de um curso de programação usando a ferramenta App inventor. A ideia é aplicar a oficina de prototipação para auxiliar os jovens na compreensão do design do aplicativo que eles irão desenvolver.

\section{Agradecimentos}

Agradecemos aos jovens participantes da pesquisa; ao Grupo de Pesquisa e Extensão em Informática, Educação e Sociedade - Onda Digital (UFBA/CNPq) e às agências de fomento Coordenação de Aperfeiçoamento de Pessoal de Nível Superior (CAPES) e Fundação de Amparo à Pesquisa do Estado da Bahia (FAPESB) pelo apoio financeiro. O autor Daniel Alves ainda agradece ao Instituto Federal de Mato Grosso (IFMT).

\section{Referências}

Baranauskas, M. C. C. (2013). O modelo semio-participativo de design. In: Baranauskas M. C. C.; Martins M. C.; Valente, J. A. (Eds.) Codesign de Redes Digitais tecnologia a serviço da inclusão social. Penso. pp. 38-66.

Barbosa, S. and Silva, B. (2010). Interação humano-computador. Elsevier Brasil.

da Rocha, H. V. and Baranauskas, M. C. C. (2003). Design e avaliação de interfaces humano-computador. Unicamp.

da Silva, N. A. N. (2012). Abordagens Participativas para o Design: Metodologias e plataformas sociotécnicas como suporte ao design interdisciplinar e aberto a participação. Dissertação de mestrado. Pontifícia Universidade Católica de São Paulo, Rio de Janeiro, Brasil.

dos Santos, J. M. O., Souza, C. M., Santos, T. A., Alves, P. M. B. F. and Santos, D. A. (2017). Contribuições da Extensão Universitária na formação social, acadêmica e 
VII Congresso Brasileiro de Informática na Educação (CBIE 2018)

Anais dos Workshops do VII Congresso Brasileiro de Informática na Educação (WCBIE 2018)

profissional dos estudantes de Computação. In: Anais do XXXVII Congresso da Sociedade Brasileira de Computação. SBC.

FORPROEX (2012). Fórum de Pró-Reitores de Extensão das Universidades Públicas Brasileiras. Política Nacional de Extensão Universitária, Disponível em: https://www.ufmg.br/proex/renex/images/documentos/2012-07-13-Politica-Nacional -de-Extensao.pdf. Acesso em: 02 set. 2018.

Interaction Design Association (2017). About \& History - Interaction design definition. Disponível em: http://ixda.org/ixda-global/about-history. Acesso em: 02 set. 2018.

Lowgren, J. (2014). Interaction Design - brief intro. In: The Encyclopedia of Human-Computer Interaction (2 ed.), Mads Soegaard and Rikke Friis Dam (Eds.). The Interaction Design Foundation, Aarhus, Dinamarca, Chapter 1.

Muller, M. J. and Druin, A. (2012) Participatory Design: The Third Space in HCI. In: Jacko, J. A. (eds.). Human- Computer Interaction Handbook, Third Edition, CRC Press, pp. 1125-1154.

Rogers, Y., Sharp, H. and Preece, J. (2013). Design de Interação. Bookman Editora.

Rosa, J. (2016). Design de Interação Multicultural: Um Framework Semioparticipativo para o (re)design da Interação de Softwares Educacionais. Dissertação de Mestrado. Instituto de Matemática e Estatística. Universidade Federal da Bahia (UFBA).

Sanders, E. B. N., Brandt, E. and Binder, T. (2010). A framework for organizing the tools and techniques of participatory design. In: Proceedings of the 11th biennial participatory design conference. ACM. pp. 195-198

Simonsen, J. and Robertson, T. (2012). Routledge international handbook of participatory design. Routledge. Taylor \& Francis. 